\title{
Understanding MACs: Moral Hazard in Acquisitions
}

\author{
Ronald J. Gilson \\ Stanford University, Columbia University, and European Corporate \\ Governance Institute
}

Alan Schwartz
Yale University

The standard contract that governs friendly mergers contains material adverse change (MAC) and material adverse effect (MAE) clauses; these clauses permit a buyer to costlessly cancel the deal if such a change or effect occurs. In recent years, the application of the traditional standard-like MAC and MAE term has been restricted by a detailed set of exceptions that curtails the buyer's ability to exit. The term today engenders substantial litigation and occupies center stage in the negotiation of merger agreements. This article asks what functions the MAC and MAE term serve, what function the exceptions serve, and why the exceptions have arisen only recently. It answers that the terms encourages the target to make otherwise noncontractable synergy investments that would reduce the likelihood of low value realizations, because the term permits the buyer to exit in the event the proposed corporate combination comes to have a low value. The exceptions to the MAC and MAE term impose exogenous risk on the buyer; the parties cannot affect this risk and the buyer is a relatively superior risk bearer. The exceptions have arisen recently because the changing nature of modern deals makes the materialization of exogenous risk a more serious danger than it had been. The modern MAC and MAE terms thus respond to the threat of moral hazard by both parties in the sometimes lengthy interim between executing a merger agreement and closing it. The article empirically examines actual merger contracts and reports results that are consistent with the analysis.

This article benefited from presentations at the American Law and Economics Association Meetings, the National Bureau of Economics Law \& Economics summer session (2003), Cambridge University, University of California at Berkeley Law School, the NYU Law and Finance Workshop, the University of San Diego Law and Political Theory Workshop, and the Wharton School of Business - University of Pennsylvania Law School joint workshop, and from comments by Barry Adler, Jennifer Arlen, Ian Ayres, Richard Brooks, Jeremy Bulow, Allen Ferrell, Victor Goldberg, Michael Klausner, Alvin Klevorick, Marty Korman, Jon Macey, Massimo Motta, Frank Partnoy, Ben Polak, Roberta Romano, Robert Scott, and two anonymous referees. We are especially grateful for the research assistance of Sarah Johnson.

The Journal of Law, Economics, \& Organization, Vol. 21, No. 2, doi:10.1093/jleo/ewi012

Advance Access publication August 19, 2005

(C) The Author 2005. Published by Oxford University Press. All rights reserved. For Permissions, please email: journals.permissions@oupjournals.org 


\section{Introduction}

Corporate assets commonly transfer under acquisition agreements and these have crystallized into a fairly standard form. ${ }^{1}$ Despite its immense commercial significance, however, the standard acquisition agreement has excited almost no academic commentary. ${ }^{2}$ This article begins a study of the standard agreement by focusing on a set of terms that now receives considerable attention from lawyers and courts, the material adverse change (MAC) clause and its equivalent, the material adverse event (MAE) clause. ${ }^{3}$

The negotiation of MACs and MAEs historically was not the object of bargaining concern. James Freund's 1975 classic Anatomy of a Merger thus treats the topic in a page and a half (Freund, 1975: 259-61). A typical term would permit the buyer not to close the transaction on the postexecution occurrence of "any change, occurrence or state of facts that is materially adverse to the business, financial condition or results of operations" of the seller (i.e., the "target"). This language is ambiguous with respect to significant issues. As an illustration, did a material change in the target's "business" include a change whose only impact would be on the target's future cash flows, because the current value of the business is the discounted value of future flows, or would additional language be required to reach this result? The term "prospects" could be added to the litany of objects of the MAC clause, or the clause could expand to specify that a change that would or was likely to have a future effect also was covered. These and other ambiguities in the typical MAC produced little litigation, despite the potentially high stakes associated with a term that could allow the buyer to cancel or renegotiate a large transaction.

The calm in acquisition practice has been shattered in recent years. Litigation over MACs and MAEs has become prominent. ${ }^{4}$ In its wake, the negotiation of these clauses has been contested and their length has exploded. The professional literature has also expanded dramatically. This change- the promotion of MACs and MAEs from the mergers and acquisitions (M\&A) chorus to center stage - provides the motivation for this article.

We attempt to make three contributions. Our primary goal is to understand the role MACs play in the structure of an acquisition agreement. We will argue that the traditional MAC form ${ }^{5}$ completes the transactional structure that

1. The standard form does not apply to hostile acquisitions, defined as transactions to which the target board does not agree. The bulk of acquisitions are not hostile, however. Even in the 1980s, the decade of the hostile takeover, $86 \%$ of acquisitions were friendly. In the 1990 s, this fraction rose to $96 \%$. Acquisitions are of major economic significance. Thus in 1995, mergers accounted for $5 \%$ of U.S. gross domestic product (GDP) and 48\% of nonresidential investment (Andrade et al., 2001).

2. An early exception is Gilson (1984).

3. Commonly the same numbered paragraph in the standard agreement will include both a MAC clause and a MAE clause. We sometimes refer to both of these clauses together as MACs.

4. See, for example, Bear Stearns Companies, Inc. v. Jardine Strategic Holdings Limited, NY Sup. Ct. \#31731/87 (1987 stock market crash); North Point Communications Group, Inc. v. Verizon Communications Inc. (2000) (decline in e-commerce sector); and Sorkin and Glater (2001) (the impact of September 11).

5. We define a MAC as "traditional" if the acquisition agreement omits setting out explicit exceptions to the acquirer's right to cancel in the event of a material adverse change or effect. 
constrains a seller's moral hazard. In the same vein, we hope to explain the change in MAC practice; that is, to identify the factors that account for the new efforts to resolve the ambiguities inherent in the traditional MAC formulation through detailed drafting. Two hypotheses could account for both the traditional role of MACs and for changes in MAC practice. The first, which we call the symmetry hypothesis, is driven by changes in corporate law that have accentuated the resemblance of the seller's interest in an executed, but not yet closed, transaction to a put option. The second, which we call the investment hypothesis, is driven by the implications of a seller's ability to make relationspecific investments during the postexecution/preclosing period that would affect the postclosing value of the new, combined company. We sometimes refer to the seller's actions as synergy investments. These are lost when deals fail to close, but do not necessarily reduce a seller's stand-alone value beyond the wasted resources themselves. In some recently expanding industries, however, wasted synergy investments could have a value reducing effect, thereby heightening the significance of terms such as the MAC that permit the buyer to exit costlessly. As we will see, the symmetry and investment hypotheses yield different predictions about the nature of the recent change in MAC practice: the symmetry hypothesis predicts an expansion of the circumstances that would permit a buyer not to close a transaction; the investment hypothesis predicts a contraction of those circumstances. Our data reject the symmetry hypothesis.

This article's second contribution is to explore the implications of our explanations for the drafting of MAC clauses and for their judicial interpretation. Finally, we focus on the contract theory implications of the MAC term. Parties commonly reject contract law's standards in favor of contractual rules. ${ }^{6}$ MACs thus are interesting from a contract theory point of view because the traditional MAC is a contractual standard-a "material adverse change" - while recent changes in drafting practice have made MACs more rule-like. We will argue that the investment theory of MACs explains both the apparent oddity of the traditional MAC and the reversion of MAC and MAE clauses to the more rule-like "contracting mean."

In Section 2, we describe the role that MACs and MAEs play in the structure of the standard acquisition agreement and we frame the competing symmetry and investment theory explanations both for the existence of a traditional MAC term and for the recent change in its formulation-from the general to the particular. Section 3 contains a simple model of the investment theory that attempts to illuminate its corporate and contract theory implications. Section 4 reports the results of our empirical analysis: Despite the real change in the character of the acquiring company's interest in an executory acquisition agreement, the data are inconsistent with the symmetry theory. Rather than observing a

6. A standard specifies permitted or prohibited actions ex post. Thus, requiring the buyer to object to a defective tender in a "reasonable time after delivery" is a standard because a court later determines whether the buyer acted reasonably; requiring the buyer to object within 10 business days is a rule. The ratio of standards to rules in contract law is very high (Schwartz and Scott, 2003). 
broadening of the acquirer's right to walk away from the transaction as a result of a change in the value of a target's business, we see the opposite: a shift in risk from the target to the acquirer through an increasingly detailed list of changes in the target's business that will not permit the acquirer to exit. We then offer an explanation for this change in the form that MACs and MAEs take: an increase in exogenous and undiversifiable risk that would be inefficiently borne by the seller were merger agreements not to allocate the risk to buyers. Section 5 briefly considers the implications of our analysis for the judicial interpretation of MAC clauses and for their drafting. Section 6 concludes.

\section{The Changing Structure and Function of the Standard Acquisition Agreement}

\subsection{The Role of Closing Conditions in a Corporate Acquisition Agreement}

Three sets of provisions reflect the three basic transactional engineering elements of a corporate acquisition agreement: representations and warranties, covenants, and conditions. Representations and warranties specify what the buyer acquires. These provisions warrant, as of the date of the acquisition agreement, such matters as the accuracy of the target's financial statements; the absence of liabilities for taxes or other matters accruing after the date of the target's most recently audited financial statements, including contingent liabilities; the ownership and condition of assets, including intellectual property, important to the operation of the target's business; the absence of pending or threatened litigation against the target; and the absence of problems in particularly important areas, such as environmental and pensions. When an acquisition agreement is executed and closed simultaneously, the agreement need contain little more than a warranties and representations article. ${ }^{7}$ The other two elements of the transactional triumvirate - covenants and conditions - are irrelevant when there is no temporal gap between execution and closing.

More commonly, a significant temporal gap does exist. A regulatory regime may require delay. For example, the regime may require a shareholder vote so that a proxy statement must be prepared and filed with the U.S. Securities and Exchange Commission (SEC). The consideration for the merger may be issuer securities, whose offer must be registered under the Securities Act of 1933. The Hart-Scott-Rodino Premerger Notification Act may require a filing and a waiting period. Agency approval of the transaction may be required, as with a bank merger. Delay also may reflect regulatory convenience, as when the parties seek a revenue ruling from the Internal Revenue Service (IRS) concerning the deal's tax consequences. Finally, delay may result from the nature of the transaction itself; due diligence for some deals can take considerable time. As a consequence

7. Other subjects, such as the contractual statute of limitations that specifies whether and for how long representations and warranties survive the closing and provisions regarding claims for breach-like "baskets" and "caps", would still demand attention. A basket is the minimum amount that the buyer's claims must sum to before the claims can be asserted. A cap is the seller's maximum liability for breaches of the representations and warranties. 
of these factors, mergers seldom close within 90 days of execution of the acquisition agreement and are sometimes delayed for as long as a year.

Covenants and conditions bridge the temporal gap between execution and closing. Covenants require or prohibit particular verifiable actions, such as complying with regulations or not declaring an unusual dividend. Conditions specify the circumstances that, when absent, permit the acquirer not to close.

Two conditions are of particular significance, and both respond to a hidden action concern. To understand the concern, realize that a seller typically has available to it a set of postexecution actions that would reduce the probability that the value of the proposed new corporate combination would fall in the interim between signing the acquisition agreement and closing the deal. Certain of these seller actions could affect specific and verifiable aspects of the target company's business. As examples, the failure to maintain a factory or to police pollution emissions could result in a decline in the factory's value or an increase in the target (and therefore the acquiring) firm's environmental liabilities. The warranties and representations term ensures that the factory is in satisfactory shape and the environmental liabilities are sufficiently low when the deal is executed. The "bring-down" condition discharges the buyer's obligation to close if the seller's representations and warranties are not true and correct on the closing date as well as on the execution date. This condition thus creates an incentive for the seller to maintain the factory and to police its emissions during the gap between execution and closing.

The MAC condition relates to that subset of seller actions that also would reduce the likelihood of a low value realization for the new company if taken, though the failure to take such an action would not itself breach the bringdown condition. The particular effect of not taking these actions, or of taking them badly, cannot conveniently be described in a contract, however. These difficult to describe actions relate to seller investments in integration - that is, in synergy - the effective pursuit of which would reduce the likelihood that the postclosing combined entity would turn out to be worth less than the parties anticipated at deal time. The standard acquisition agreement, we argue, creates an incentive for the seller to invest in synergy by permitting the buyer to exit if the target's business suffers a "material adverse change," or experiences an event that results in a "material adverse effect," on a litany of target characteristics, including the target's business, its financial condition, and the results of its operations. ${ }^{8}$

8. The MAC term also can be drafted to extend the time period covered by the representations and warranties. Because the current value of the target's business is the discounted present value of future cash flows, a change occurring in the postclosing/preexecution period that affects future cash flows would affect the current value of the business, and thus may give the buyer with MAC protection a right not to close even if the express warranties only spoke to current values. This timing issue has been addressed in litigation over whether a simple reference to "business" is sufficient to give the MAC term a forward-looking character, or whether an additional term such as "prospects" is necessary. 
Finally, there is a question whether a MAC would permit a buyer not to close if a low value for the combined company was realized in consequence of an exogenous event rather than because of an action that the target took or failed to take. The traditional MAC formulation is ambiguous regarding exogenous risk. As an example of the issue, the bring- down condition will be satisfied if a company's backlog is the same at closing as at the deal's signing. But suppose the target manufactures military helicopters and that, in the interim between signing and closing, the Defense Department announces a new policy that will substitute planes for helicopters in providing support for attacking troops. The new policy would materially reduce the expected gain from a merger with the target - future cash flows would decrease because of a decrease in future orders - but neither party could have affected the policy's adoption. As we will see, whether parties intend the MAC to impose such an exogenous risk on the seller or the buyer will permit us to distinguish between the symmetry and investment theories.

\subsection{Explanations for MACs and Changes in MAC Practice}

2.2.1 The Symmetry Theory: The MAC as an Offsetting Option. Parties to friendly acquisitions did not worry seriously about hostile competing bids before the 1980s. ${ }^{9}$ Economic and legal changes in the 1980s altered this happy state (that is, happy for everyone but the shareholders of targets). The capital market and transaction technology evolved such that financing for a competing bid could be raised before a friendly transaction could be closed, thus making real the requirement that target shareholders approve the transaction. ${ }^{10}$ A set of Delaware cases also established that target managers were required to accept the highest bid, regardless of their preference for the friendly acquirer. Indeed, the managers were required to seek out the highest bid. ${ }^{11}$ In a later round of cases, the courts further restricted the ability of parties to a friendly deal to prevent the target from considering competing bids by agreeing in the acquisition agreement to "no shop" or "no talk" clauses. ${ }^{12}$ The result of these economic and legal innovations was to enable the seller always to accept a higher competing bid or to compel a renegotiation of the price; acquisitions require target shareholder approval, whether explicitly by vote or implicitly by tender, and the target shareholders would refuse consent to an initial offer in the face of another buyer's higher bid.

9. For an early recognition of the effect of a hostile competitive bid on the structure of a friendly deal, see Freund and Easton (1979).

10. These developments are explained in Gilson (forthcoming).

11. See MacAndrews \& Forbes Holdings, 506 A.2d 173 (Del. S. Ct. 1986); Mills Acquisition Company v. Macmillan, 559 A.2d 1261 (Del. S. Ct. 1989); Paramount Communications v. QVC Network, Inc., 637 A.2d 34 (Del. S. Ct. 1993).

12. See, for example, Phelps Dodge Corp. v. Cyprus Amax Minerals Co., 1999 WL 1054255 (Del. Chancery, Sept. 27, 1999); Ace Limited v. Capital Re Corp., 747 A2d 95 (Del. Chancery 1999). Most recently, the Delaware Supreme Court cast substantial doubt on a target company's ability to commit absolutely to a bidder even after a full and fair auction; Omnicare v. NCS. Healthcare, Inc., 822 A.2d 397 (2003). 
On the symmetry theory, the ability of the seller to go elsewhere, when fully appreciated, would have seriously curtailed acquisition activity in the absence of a MAC. To see why, realize that a friendly acquirer is bound by the acquisition agreement it had signed, while the target is not bound (its shareholders could refuse consent), and target management is legally required to attempt to improve on the buyer's offer. ${ }^{13}$ If the seller's value at closing time, either to the buyer or to another acquirer, is above the bid price, the seller would either renegotiate the bid price or exit to accept a better offer. If the seller's ex post value were below the bid price, the seller in a contract without a MAC would make the original deal. The buyer thus would bear the full cost of low realizations, but receive only part of the gain (or no gain) from high realizations.

A seller functioning in this economic and legal environment has an incentive to offer a MAC to potential buyers. A broadly drafted MAC would increase a buyer's expected gain from an acquisition, and this would increase the likelihood that the seller would receive bids. Just as the seller would exit if its value turned out to be above the bid price, the buyer now would exit if the seller's value turned out to be below. Transaction costs would keep the seller in the deal if its value turned out to be slightly high and would keep the buyer in the deal if value turned out to be slightly low. When the standard acquisition agreement has a traditional MAC, the acquirer thus no longer commits to purchase the bottom half of a probability distribution, but instead only commits to purchase if the realized value is close to the negotiated price.

Parties, however, apparently can use two other contractual techniques to respond to the seller's put option. First, parties can reduce the value of the seller's put by reducing the merger price. Second, parties can require the seller to pay a break-up fee if it exercises its option to accept a higher bid elsewhere. ${ }^{14}$ These techniques have serious disadvantages relative to a MAC. The first technique would be difficult to implement because real options are not traded, and so are hard to price. The second technique also would be difficult to implement because, under Delaware law, break-up fees that exceed $2 \%$ to $4 \%$ of transaction value pose a significant risk of nonenforcement. Hence parties may be unable to use a break-up fee in the appropriate amount. A MAC thus appears to be the best response to the parties' asymmetry concern.

This symmetry theory has a testable implication. To create a call for the buyer that is symmetric to the put the Delaware courts gave to the target, the formulation of the MAC term should shift to the target the risk of exogenously caused reductions in the value of the new corporate combination. In particular, by the late 1980 s the MAC clause would clarify the traditional formulation by specifying that the existence of such value reducing factors as unfavorable economic

13. In many cases, approval requirements for an acquisition are asymmetric, as between the seller and the buyer. The seller's shareholders must approve the transaction because it involves the elimination of the seller as an independent firm. The buyer's shareholders typically need not consent, however, unless the transaction involves the issuance of more than $20 \%$ of the buyer's stock. Thus the buyer's board commonly can make a binding offer to purchase.

14. See generally, Gilson (1982). The positive role of break-up fees in inducing bidder entry is analyzed in Bates and Lemmon (2003). 
conditions in the general economy or in the target's industry would permit the acquirer not to close.

2.2.2 The Investment Theory. The investment theory rests on the ability of a seller, in the postexecution/preclosing period, to make relation-specific investments that will affect the value of the combined company. These investments fall into three categories. Initially, the success of an acquisition may depend on early efforts to facilitate integration, for example, because the acquisition is motivated by the potential for postclosing synergy. ${ }^{15}$ Getting a head start on integration could then be valuable, especially in competitive industries that experience rapid technological change. In such industries, the merger announcement, rather than the closing, triggers a competitive response. As examples of investment, the target company may begin the process of integrating its product line with that of the acquirer by suspending or canceling the development or improvement of products; may freeze investment in capabilities that the acquirer already possesses; may shift its research and development to fit the anticipated postclosing strategic plan; and may discuss with its customers the buyer's capabilities in markets where the buyer has been a competitor.

The second investment category comprises efforts by the target company to retain the cohesiveness of its workforce. The announcement of a friendly transaction could lead employees to suspect layoffs or unwanted changes in the work environment. These expectations could cause more mobile, and likely more valuable, employees to become less focused on the target and more focused on their own futures, with the potential of an adverse selection cascade. The third investment category focuses on seller efforts to preserve the expected profitability of the new enterprise. A target firm's customers and suppliers may reconsider their relations with the target in anticipation of the postclosing situation. Also, competitors may attempt to exploit these uncertainties. The failure of a seller to expend effort in retaining a workforce and in preserving relations with customers and suppliers in the sometimes lengthy interim between execution and closing thus could materially reduce the value of the new company. ${ }^{16}$

Certain of the actions that a seller could take share a common characteristic: they may materially reduce the target's stand-alone value if the deal fails to close. This is particularly true of investments in integration, where the target may reveal information to the buyer that the buyer, or other firms, could use to the seller's disadvantage. In addition, the competitive cost of strategic steps undertaken in expectation of closing, but with negative

15. Synergy as an acquisition motive is discussed in Gilson and Black (1995: chap. 8).

16. The model in Section 3 uses the phrase "investment" to refer to actions the seller can take to prevent the loss of employees, customers, and opportunities. The bring-down condition does not create an incentive for a seller to take all of these actions. As examples, a seller seldom warrants the continued existence of business opportunities or covenants that it will take actions to mesh its research and development $(\mathrm{R} \& \mathrm{D})$ program with that of the buyer. 
consequences for the target if the transaction does not close, could be substantial in some industries. ${ }^{17}$

The investment theory follows from this story. Regarding the intuition - the model is set out below-consider the seller's incentives under an acquisition agreement without a MAC. Assume that if the seller failed to take actions in any of the three investment categories, the new company's expected value would be distributed normally with a low of 1 , a high of 10 , and a mean of 5. And suppose the acquisition price is four. The effect of seller investment on our theory is to shift probability mass toward the high end of the value distribution. In this example, investment would cause values of two and three to become less likely. The new mean, for example, would increase to six. The seller could profit from a one unit increase in the mean because the seller could use its ability to exit to renegotiate for a share of the gain. Thus the seller's incentive to invest, when there is no MAC, would be greater than zero. Efficiency, however, requires the seller to invest until the marginal gain - the marginal reduction in the likelihood of low value realizations - equals the marginal cost. Instead, the seller will invest too little relative to the social optimum because the seller has little interest in reducing the likelihood of low realizations; if the new company's value in this illustration turns out to be two or three, the seller will enforce the contract price of four. ${ }^{18}$

The MAC responds in a subtle way to this moral hazard problem. To see how, assume that parties cannot contract directly on the value the new company would have because values are unverifiable and that it is too costly to describe in a contract the full set of value enhancing seller actions. A MAC permits the buyer to exit costlessly if the seller experiences a material adverse "change" or "effect" in its "business or financial condition." These changes or effects have three characteristics: they would be verifiable if material; they correlate negatively with the value the new corporate combination would have; and they

17. The postexecution/preclosing activities in Hewlett-Packard's acquisition of Compaq illustrate the intensity of integration efforts and the potential risks if the transaction does not close. Prior to closing, more than 1000 employees of both companies devoted more than one million hours to integration planning (Wall Street Journal, May 8, 2002: B1). This effort included choosing which of the two companies' products would survive in each product line as well as developing three-year plans for each surviving line. These choices had obvious effects on the lines that were to be discontinued (Wall Street Journal, April 28, 2003: A1). At the employee level, the top three tiers of management were selected from among the two companies' managers well before closing (Wall Street Journal, April 28, 2003: A1). At the same time, customers of both companies were the object of intense attention from competitors. One customer recounted that "he gets as many as five calls a week from other computer makers. The pitches frequently aren't subtle. 'You may want to be aware that such-and-such H-P or Compaq product won't be a survivor of the deal' [the customer] quotes one sales representative as saying" (Wall Street Journal, March 20, 2002: A1). To the same effect, a postexecution/preclosing survey of Compaq Unix customers showed that they would be "less likely" to buy from the merged company (Wall Street Journal, January 25, 2002: A13).

18. Recalling the three investment categories summarized above, seller investment primarily involves the expenditure of effort: to reassure a workforce, to explain the deal to customers and suppliers, to share information with the acquirer. Because investment largely involves effort and thought rather than the expenditure of serious cash, its cost is borne by the seller, not the buyer. We capture this insight in the formal model below by assuming that investment does not reduce the target's stand alone value. 
would be less likely to occur if the seller took the investment actions described above. ${ }^{19}$ Thus the effect of the MAC is to reduce the seller's insurance against low realizations. The seller's best response is to choose an investment level that is closer to the social optimum. ${ }^{20}$

The investment theory generates three testable predictions. First, acquisition agreements had MACs before the legal developments summarized in Section 2.2.1. Second, MAC drafters will resolve the ambiguity in the traditional MAC formulation by creating exceptions to the traditional MAC that would impose exogenous risk on the buyer. Third, the incentive of parties to resolve ambiguity in this way increases when the combination of exogenous risk and the seller's investment could cause the seller's stand-alone value to decrease should the deal not close. Regarding the second prediction, a buyer who can cancel for exogenous risk will renegotiate the price downward when the materialization of exogenous risk will cause the deal to become unprofitable for it at the original price. This allocates more of the exogenous risk to the seller. As we will see, conditional on deals closing, buyers are better able to reduce the impact of and insure against exogenous risk. On the assumption in our model that the parties are risk neutral, the acquisition agreement should allocate the entire risk to the buyer when the efficiency gains from this risk allocation exceed the transaction costs of creating MAC exceptions. Regarding the third prediction, when a MAC lacks exceptions, the bargaining game the parties play ex post will allocate to the seller a greater share of exogenous risk when the seller's value will decrease after a failed deal. This further reduces the efficiency of a merger agreement without MAC exceptions and so increases the parties' incentive to create them.

It is helpful to make the last two predictions more concrete. The investment theory holds that an efficient acquisition agreement will impose endogenous risk on the seller and exogenous risk on the buyer. The need to make explicit the exogenous risk allocation should become more pressing as exogenous risks become more severe. The increased volatility of capital and product markets in the 1990s thus suggests that explicit MAC exceptions should become more prevalent over the course of that decade. ${ }^{21}$ These exceptions would impose

19. Buyers have called MAC events, sometimes successfully, when, for example, the seller was late with a product's development; it experienced a material shortfall in inventory; its recent revenues dropped substantially; its operating margins declined substantially; it began to experience operating losses; it had a negative accounting net worth as a consequence of conducting (bank) mergers without using available government assistance; it incurred large losses as a consequence of a recent entry into a new market.

20. We later argue that corporate law creates efficient incentives for the buyer to invest in synergy. This article thus considers only seller investments when attempting to explain the content of the standard acquisition agreement.

21. The increased capital market volatility can be seen from, for example, the Chicago Board of Options Exchange volatility index (CBOE VIX), a measure of near-term volatility conveyed by stock index option prices. This index increased substantially over the period from 1994 to 2003, the period during which MAC exceptions became part of acquisition practice. Time-series data on the value of the VIX is available at www.cboe.com/vix. Over this period, product markets were characterized by the wide-ranging impact of technology in creating new markets, such as the Internet, Worldwide Web, and fiber optics, and by the reframing of existing markets, such as the impact of biotechnology on the traditional pharmaceutical industry. 
exogenous risk on the buyer by excluding from the definition of a material adverse change or effect such matters as unfavorable changes in the general or industry-specific economic environment. We then extend this argument to predict that MAC exceptions should be especially common in connection with the acquisition of companies where human capital and technological know-how are critical inputs and where technological change is rapid. Such companies, as argued above, are most exposed to information leaks that could aid competitors, customers, and suppliers; to anticipatory defections by employees; and to anticipatory reactions by competitors, particularly to poach employees and customers. These companies - technology-based targets best fit the description - will more likely suffer declines in stand-alone value when deals fail.

\section{A MAC Model}

\subsection{The Model}

A risk-neutral seller and a risk-neutral buyer enter into a contract $(d, \tau)$ at $t^{0}$ for the sale of the seller's company, where $d$ is the price and $\tau$ is a vector of terms describing what is purchased. The seller's stand-alone value is denoted $v_{\mathrm{T}}$ and the acquirer's stand-alone value is denoted $v_{\mathrm{A}}$. At $t^{1}$, the seller can take an action, denoted $e$, that will affect the value that the proposed corporate combination will create. The action is referred to as choosing an investment or effort level. The set of potential actions available to the seller, and the various ways in which the actions can be performed, are sufficiently complex so that we assume parties cannot write a contract specifying what an efficient seller investment would be. ${ }^{22}$ The seller's investment, along with the subsequent realization of the state of the world $(\omega)$, determine the value of the combined entity: $v_{\mathrm{AT}}(e, \omega) \in\left(0, v_{\mathrm{h}}\right)$, where $v_{\mathrm{h}}$ is the highest possible realized value. For convenience, we let $v_{\mathrm{AT}}=v$. If the merger turns out not to produce a surplus, then $v=v_{\mathrm{A}}+v_{\mathrm{T}}$, which is denoted $v_{\mathrm{ng}}$.

Seller investment is stochastic. The probability that the firm will come to have a value that is less than or equal to any realized value $v$ is $F(v(e ; \omega))$, given an effort level $e$. The density associated with $F(v(e ; \cdot))$ is $f(v(e ; \cdot))$. Investment improves this distribution by reducing the likelihood of realizing low values. ${ }^{23}$ We assume

Assumption 1. $F(v(e ; \omega)) \geq 0$.

22. The contracting cost has two elements. First, it is costly (or impossible) to describe a complex set of actions and the circumstances in which they should be undertaken. Second, it is costly to monitor the seller to ensure that it complied with its contractual obligations. The cost of enforcing a contract clause actually is a cost of writing it. We assume that total writing costs, so defined, are sufficiently great as to preclude contracting directly on the seller's investment behavior. This is a standard assumption in contract theory models and is consistent with transactional practice. Covenants typically contain explicit prohibitions rather than specify a set of actions the seller is to perform.

23. Formally, we suppose that $\delta F(v(e ; \omega)) / \delta e<0$ for all $v \in\left(o, v_{\mathrm{h}}\right)$. In other words, if $e>e^{\prime}$, then $F(v(e ; \omega))$ strictly dominates $F\left(v\left(e^{\prime} ; \omega\right)\right)$ in the sense of first-degree stochastic dominance. To ensure interior solutions to optimization problems, we also make the standard assumptions that $f^{\prime}(v(e ; \omega))>0 ; f^{\prime \prime}(v(e ; \omega))<0 ; f(v(\infty ; \omega))<1$. 
Assumption 2. The acquisition agreement does not contain a MAC, but does contain the other terms described above.

Assumption 3. $v_{\mathrm{T}}(e, \omega) \geq v_{\mathrm{T}} \forall e, \omega$.

Assumption 4. $d>v_{\mathrm{T}}$.

Because $v_{\text {ng }}>0$ and Assumption 1 has $v=0$ occurring with positive probability, Assumption 1 permits an acquisition to be ex post inefficient (then $v<$ $v_{\text {ng }}$ ). Assumption 2 permits us to focus on the possible contribution of a MAC to welfare. Assumption 3 holds that seller investments in synergy may increase, but will not reduce the seller's stand-alone value. Section 3.3 below, discussing exogenous risk, relaxes Assumption 3 to consider the possibility that investment can reduce $v_{\mathrm{T}}$ when a deal fails to close. Regarding Assumption $4, d=v_{\mathrm{T}}$ is an individual rationality constraint. We assume that $d$ exceeds the seller's stand-alone value because no two targets are exactly alike, so that a target will have some bargaining power at the negotiation stage.

At $t^{2}$, the parties observe the value the combined company will have. ${ }^{24}$ The parties then decide whether to make the deal at the original price $d$, to cancel the deal and renegotiate the price, or to abandon the deal. At $t^{3}$, the parties conclude a deal under the original or under the renegotiated price, or do not transact.

As shown in Section 2.2.1, corporate law effectively gives sellers an option not to be bound by the acquisition agreement. Suppose then that the new company's value turns out to be high; the seller then refuses to ratify the deal. This wipes the slate clean legally; the seller is not bound and the buyer need not pay the price $d$. If an acquisition would be ex post efficient, however, there is surplus to share, so the parties will renegotiate. We model renegotiation as a Nash bargaining game with disagreement points that function as threat points: the parties' bargaining weights are denoted $\alpha_{\mathrm{A}}$ (for the acquirer) and $\alpha_{\mathrm{T}}$ (for the seller), with $\alpha_{\mathrm{A}}+\alpha_{\mathrm{T}}=1 .{ }^{25}$ The renegotiation surplus is denoted $s$, where $s=v-\left(v_{\mathrm{A}}+v_{\mathrm{T}}\right)=v-v_{\mathrm{ng}}$. Hence if the target calls the deal off and renegotiates, it will receive the new price $d_{\mathrm{r}}=v_{\mathrm{T}}+\alpha_{\mathrm{T}} s$, while if the target lets the deal stand, its payoff is the original price $d$. A seller thus will renegotiate when $d_{\mathrm{r}}>d$. We let $v_{\mathrm{m}}$ denote the value for the new company that makes this expression an equality.

This analysis implies that the combined company's value can fall within five ranges. If, despite seller investment, $v<v_{\text {ng }}$ is realized, the deal is ex post inefficient. Both society and the buyer would like the merger to be canceled. If the value is between $v_{\text {ng }}$ and $v_{\mathrm{h}}$, the deal is ex post efficient and should be concluded. If the value is between $v_{\text {ng }}$ and $d+v_{\mathrm{A}}$, the buyer would cancel

24. Values are assumed to be observable, but not verifiable. The motivation for assuming a lack of verifiability is the large expense and considerable time that it takes to value sizable companies in judicial proceedings.

25. This game, which is commonly used in the contract theory literature, requires each party to receive a payoff that equals the payoff of its next best option plus an exogenously determined share of the surplus that remains after the disagreement payoffs have been made. 


\begin{tabular}{llllll}
\hline$/ 0$ & $/ \mathrm{v}_{\mathrm{ng}}$ & $/ \mathrm{d}$ & $/ \mathrm{d}+\mathrm{v}_{\mathrm{A}}$ & $/ \mathrm{v}_{\mathrm{m}}$ & $/ \mathrm{v}_{\mathrm{h}}$
\end{tabular}

Figure 1. Value Ranges of Combined Company.

if it could; a deal at $d$ would cause it to incur a loss. ${ }^{26}$ If the target value is between $d+v_{\mathrm{A}}$ and $v_{\mathrm{m}}$, the parties will voluntarily complete the merger at the contract price: the buyer will earn a positive profit and the seller prefers the price to renegotiation. ${ }^{27}$ Finally, if the value is greater than $v_{\mathrm{m}}$, the seller calls off the deal and renegotiates. These five ranges are illustrated in Figure 1, where the values are of the new corporate combination.

Remark 1. A seller's investment can increase value in two ways. First, though the seller's investment is specific to a combination with the buyer, the seller's actions could reveal that it would be a good merger partner for other companies. This will increase the likelihood of receiving outside offers and so increase the seller's value. Second, the seller's actions could increase the expected revenue the proposed corporate combination would earn. In either case, the seller in the model will renegotiate when the new company's value exceeds $v_{\mathrm{m}}$.

Remark 2. Buyers can take two kinds of value-affecting actions in the interval between signing a deal and closing it. One kind would protect the new company against exogenous risk. We defer discussion of this action category to Section 3.3. The second category is comprised of investments in synergy that can prevent declines in (and may increase) the value of the new company. Nevertheless, we model synergy as an investment problem that only the seller faces for two reasons:

(i) The buyer has an incentive to delay investing in synergy until after the deal closes.

(ii) Corporate law gives the buyer appropriate incentives to invest when its investments are best made in the postexecution/preclosing period, so there is no need to motivate the buyer by contract.

Regarding reason (i), the buyer can invest in synergy before or after the deal closes. If a buyer's preclosing actions would increase the value of the new company sufficiently, the seller would cancel and renegotiate. Since the seller would have bargaining power in the renegotiation, the buyer could not realize the full return from successful pre-closing synergy investments. Therefore,

26. The buyer breaks even when the difference between the value of the combined company and the buyer's stand-alone value - the buyer's gain - equals the price. The buyer thus loses money when $v-v_{\mathrm{A}}<d$, which implies that the buyer prefers cancellation when $v<d+v_{\mathrm{A}}$.

27. Note that $v_{\mathrm{m}}>d+v_{\mathrm{A}}$. To see why, recall that the seller accepts the deal at the contract price whenever $d>v_{\mathrm{T}}+\alpha_{\mathrm{T}}(s)$. Recalling that $s=v-v_{\mathrm{ng}}$ and substituting the buyer's break-even point of $d+v_{\mathrm{A}}$ for $v$, this inequality reduces to $d>v_{\mathrm{T}}$, which holds by assumption. Thus the seller always accepts the deal when the realized value equals the buyer's break-even point, while $v_{\mathrm{m}}$ is defined as the realized value at which the seller is indifferent between acceptance and renegotiation. 
unless short-term discount rates are high, the buyer does better delaying investment to the post-closing period, where it can then capture the full return.

Regarding reason (ii), investment by a party in the model is motivated by the ability of the other party to exit. As will be seen, a contract term is needed to give the buyer this right, but corporate law permits the seller always to exit, so no contract term is needed.

\subsection{The Effect of MACs on Investment}

The initial question is what investment level the seller should choose from a social point of view. As we assume no externalities, the social surplus from a deal is $s=v-v_{\text {ng. First-best efficiency requires }}$

(i) A deal should close if and only if $v \geq v_{\text {ng }}$.

(ii) The seller should choose the effort level $e^{*}$, where

$$
e^{*} \equiv \operatorname{argmax}_{\mathrm{e}} \int_{\left(\omega \mid v(\cdot) \geq v_{\mathrm{ng}}\right)} v(e ; \omega) d F(\omega)-e .
$$

The first-order condition for a social maximum is

$$
\int_{v_{\mathrm{ng}}}^{v_{\mathrm{h}}} v_{\mathrm{e}}(e ; \omega) d F(\omega)=1 .
$$

where subscripts denote partial derivatives. Thus $v_{\mathrm{e}}(e, \omega)=\delta v(e ; \omega) / \delta e$.

An acquisition agreement without a MAC will not create first-best investment incentives for two reasons. First, the seller does not have all the bargaining power in the renegotiation game; thus it cannot capture the full return from investment. Second, the contract sets a floor of the price $d$ under the seller's possible payoffs. If realized value is in the range $v_{\mathrm{ng}} \ldots v_{\mathrm{m}}$, the seller will enforce the deal at the price $d .^{28}$ The seller's problem thus is to choose $e$ to maximize

$$
\begin{aligned}
& \left\{\left(1-F\left(\omega \mid v \leq v_{\mathrm{m}}\right)\right) v_{\mathrm{T}}+\alpha_{\mathrm{T}}\left[\int_{v_{\mathrm{m}}}^{v_{\mathrm{h}}}\left\{v(e, \omega)-v_{\mathrm{ng}}\right\} d F(\omega)\right]\right\} \\
& +F\left(\omega \mid v \leq v_{\mathrm{m}}\right) d-e .
\end{aligned}
$$

The term in large braces is the seller's expected payoff in the high value state, when the seller calls the deal off and renegotiates; the second term is the expected value of receiving the price $d$ when the seller lets the deal stand; and the third term is the effort level the seller chooses. The seller's first-order condition for a maximum thus is

$\left.\alpha_{\mathrm{T}} \int_{v_{\mathrm{m}}}^{v_{\mathrm{h}}} v_{\mathrm{e}}(e ; \omega)\right) d F(\omega)=1$.

28. We discuss in Section 3.4 the case when a deal would be ex post inefficient $\left(v<v_{\mathrm{ng}}\right)$. 
The left-hand side of Equation (2) is smaller than the left-hand side of Equation (1) because the integrand is over a smaller range and because the seller's renegotiation payoff, $d_{\mathrm{r}}$, is less than the value of the combined company $v$. The seller thus will choose a lower level of investment without a MAC than is socially optimal. This result obtains for two reasons: the seller cannot capture the full gain from high realizations because it has less than all of the bargaining power; and the fixed price contract insures the seller against low realizations.

A contract with a MAC will improve the seller's investment incentives by lowering the floor under the seller's payoffs in bad states. When the new company's realized value is in the range $v_{\text {ng }}$ to $d+v_{\mathrm{A}}$, the buyer will use the MAC to cancel the deal. The parties will then renegotiate. The seller will receive a share of the ex post value of the combined company, but the expected value of this, by definition, is less than the original price $d$. Hence the seller now bears part of the cost from low realizations.

Formally, when the merger agreement has a MAC, the seller chooses $e$ to maximize

$$
\begin{aligned}
& \alpha_{\mathrm{T}}\left[\left(\int_{v_{\mathrm{m}}}^{v_{h}} v(e ; \omega) d F(\omega)+\int_{v_{\mathrm{ng}}}^{d+v_{\mathrm{A}}} v(e ; \omega) d F(\omega)\right)\right] \\
& \quad+d\left[\left(F\left(\omega \mid v \leq v_{\mathrm{m}}\right)-F\left(\omega \mid v \leq d+v_{\mathrm{A}}\right)\right]-e .\right.
\end{aligned}
$$

The second term in the first set of brackets is the seller's expected payoff when value turns out to be in the range $v_{\mathrm{ng}}$ to $d+v_{\mathrm{A}}$, the buyer uses the MAC to exit, and the parties then renegotiate the price. The second bracketed term is the expected value of receiving the price $d$. The seller's first-order condition for a maximum with a MAC becomes

$\alpha_{\mathrm{S}}\left[\int_{v_{\mathrm{m}}}^{v_{\mathrm{h}}} v_{\mathrm{e}}(e ; \omega) d F(\omega)+\int_{v_{\mathrm{ng}}}^{d+v_{\mathrm{A}}} v_{\mathrm{e}}(e ; \omega) d F(\omega)\right]=1$.

The left-hand side of Equation (3) is larger than the left-hand side of Equation (2), thereby implying that the seller has a greater incentive to invest when the contract has a MAC than when it does not. With a MAC, the seller is "insured" over a smaller part of the possible return space and at risk over a larger portion of that space. As a consequence, the seller's incentive to invest is increased. This reasoning yields

Proposition 1. A MAC increases to a level that is closer to the socially optimal level the seller's investments in synergy in the post-execution/preclosing period.

Remark 3. A seller's incentive to invest would improve if the seller could make a take it or leave it offer to the buyer at the ex post bargaining stage. The contract theory literature exhibits mechanisms that permit such offers [see Hart and Moore (1999) and Maskin and Tirole (1999)]. We exclude these 
mechanisms from consideration because they are not robust to renegotiation under the contract law rules that now obtain. ${ }^{29}$

Remark 4. The MAC permits the buyer to exit in the event of a low realization, and this exit right motivates the seller to invest to reduce the likelihood of these realizations. Corporate law permits the seller to exit in the event of a high realization, and this exit right motivates the buyer to invest to increase the likelihood of these realizations. This article therefore can treat motivating synergy investment as a problem that only the buyer faces when attempting to explain the content of the standard acquisition agreement.

Remark 5. The traditional MAC is an unusual term from a contract theory point of view because it is a standard ("material adverse change") rather than a rule. Standards are less costly for parties to create than rules. ${ }^{30}$ Contracting parties, however, commonly prefer to create rules when the discretion that a standard confers would provide an opportunity for moral hazard. For example, Section 2-615 of the Uniform Commercial Code permits a seller to avoid a contract if its performance "has been made impractical by the occurrence of a contingency the non-occurrence of which was a basic assumption on which the contract was made...." A seller for whom a contract has turned out badly has an incentive to breach in the hope that the vagueness of this standard would permit it to avoid liability. Parties routinely respond by contracting out of Section 2-615 in favor of writing precise force majure clauses. In contrast, here the party with discretion has appropriate incentives. The MAC, that is, permits the buyer to exit when realized value is low, and it is the buyer's credible threat to act that improves the seller's incentive to invest. Parties to acquisition agreements thus can realize the virtues of a standard without increasing their incentive to engage in moral hazard.

\subsection{Exogenous Risk and MAC Exceptions}

Neither party, by definition, can affect whether an exogenous value affecting risk will materialize. The buyer is the more efficient risk bearer, however. To see why, it is helpful first to note that if exogenous events cause the value of the corporate combination to fall below the parties' stand-alone values $\left(v<v_{\mathrm{ng}}\right)$, the buyer will exit regardless of what the contract provides. ${ }^{31}$ Hence the parties' problem is to allocate exogenous risk for states of the world in which the deal is ex post efficient and thus will close.

A risk whose materialization cannot be prevented should be assigned to the party who has the appropriate incentive to take value insuring or value preserving actions. To understand the parties' incentives, suppose that the seller and the buyer both have available to them a set of actions that could cushion the effect of exogenous risk. Under the traditional MAC, the seller would have an

29. Law reforms could authorize courts to enforce no renegotiation terms [see Schwartz and Scott (2003) and Schwartz and Watson (2004)] or could permit parties to deter renegotiation by imposing penalties (Edlin and Schwartz, 2003).

30. It is easier to tell a party to behave "reasonably" than to tell the party just what it should do.

31. The parties' actions when a deal would be ex post inefficient are considered in Section 3.4. 
incentive to take risk cushioning actions if their impact would be manifest in the interim between signing and closing the deal. Now let this MAC be interpreted such that the seller would bear risks whose effect would be largely felt after the closing. The seller would have little incentive to ameliorate those risks because payment of the price leaves the seller indifferent to the value of the new enterprise. In contrast, the buyer does have an incentive to take actions in the interim between signing and closing that would affect risks that materialize largely after closing. This is partly because the buyer can capture the full gain from actions whose effects will be realized after the seller is paid. ${ }^{32}$ Of greater significance, the buyer can coordinate the responses across both companies (the seller will not object because it is protected from the effect of the exogenous event by the MAC exception) and, without the buyer's intervention, the seller will ignore "future risks." Either the buyer will act (directly or through the seller) or no one will.

An alternative way to put this point is to suppose that the seller bore exogenous risk and a value reducing risk materialized. The buyer would use the MAC to trigger a renegotiation, but this would not occur at once. In the interim, neither party would have appropriate incentives to invest in cushioning the risk because bargaining power between them is shared. In contrast, if the buyer bore exogenous risk, it would have an incentive immediately to invest efficiently in risk cushioning.

For these reasons, an efficient acquisition agreement would impose on the buyer those exogenous risks whose impact would be felt largely after the buyer takes control of the new enterprise. An obvious example is the risk that the law regulating the new entity would change. Another example is a recession in the parties' industry. The impact of a typical recession likely extends beyond the interim between signing an acquisition agreement and closing the deal. Also, the effect of typical buyer responses - for example, positioning the company for an economic upturn - ordinarily would be realized after the deal closes. The buyer's greater ability to respond to long-term exogenous risk and the buyer's good incentives to do so imply the efficiency of allocating these risks to buyers.

Relating this reasoning to the MAC term, exogenous risk makes relevant two possible states of the world. First, the realization of exogenous risk reduces the value of the new company, but value would still be high enough to permit the buyer to make a positive profit at the transaction price $d$. In this event, the MAC's risk allocation would not matter because the deal would close at $d$ and the buyer would bear the full cost of the exogenous change or effect. This gives the buyer an incentive to take value preserving or insuring actions. Second, the materialization of exogenous risk causes the value of the new company to fall such that the buyer would incur a loss if it bought at the deal price. If the MAC imposed exogenous risk on the buyer, it again would pay $d$; as a consequence, the buyer would optimize against more of the return distribution that exogenous risk could generate.

32. See Remark 2 above. 
In contrast, if the seller bore exogenous risk, the buyer would cancel the deal when it would otherwise incur a loss, and the parties then would renegotiate to split the deal's surplus $s .{ }^{33}$ The renegotiation price would be $d_{\mathrm{r}}=v_{\mathrm{T}}+\alpha_{\mathrm{T}} s<d$ because the buyer could not make a profit at the original price. Renegotiation, by lowering the price, thus would reduce the effect that exogenous risk would otherwise impose on the buyer - the new owner. Anticipating this outcome, the buyer would invest too little in risk cushioning or insuring activities. This analysis predicts that parties would clarify the traditional MAC formulation by allocating future or long-lasting exogenous risks to the buyer when the efficiency loss from a traditional MAC would exceed transaction costs.

We can extend this analysis to the case where the failure of a deal to close would reduce the seller's stand-alone value. Again consider the case where the materialization of exogenous risk would cause the value of the new company to fall below the buyer's break-even point. If the parties fail to conclude a deal, the buyer's stand-alone value would remain $v_{\mathrm{A}}$, but the seller's stand-alone value now is assumed to fall to $v_{\mathrm{T}}-\Delta v_{\mathrm{T}}$. The surplus from doing the deal thus would increase to $s^{+}=v+\Delta v_{\mathrm{T}}-v_{\mathrm{ng}}>s$. Therefore, when the agreement contains an unqualified MAC and the buyer cancels to initiate a renegotiation, the renegotiation price will be below, by the amount $\alpha_{\mathrm{T}} \Delta v_{\mathrm{T}}$, the renegotiation price calculated above, when a deal's failure was assumed not to affect the seller's stand-alone-value. The buyer now bears less exogenous risk than before and its incentive to take value cushioning activities correspondingly diminishes. Put another way, when a failed deal would cause the seller's stand-alone value to fall, the width of the value distribution against which the buyer should optimize has widened, but a traditional MAC could not appropriately increase the buyer's incentive to act. The efficiency loss from an unqualified MAC thus is largest in the value reduction case, so MAC exceptions are more likely to be seen there. We summarize this reasoning in

Proposition 2. Contract writing costs aside, it is efficient for the standard acquisition agreement to allocate endogenous risk to the seller and exogenous risk to the buyer, that is, to contain a traditional MAC qualified by a set of MAC exceptions.

Remark 5. The likelihood that MAC exceptions are present in an acquisition agreement should be higher in industries where the failure of a deal to close would result in a decrease in the seller's stand-alone value. For the reasons given in Section 2.2.2, technology mergers will most often fulfill this condition.

Remark 6. MAC exceptions should more closely resemble rules than standards. The phraseology of the traditional MAC arguably comprehends both endogenous and exogenous risk. This ambiguity is best clarified by rules. In addition, the materialization of an exogenous risk that would materially lower the long-term value of a corporate combination often would be verifiable. Thus parties could contract on such risks.

33. Recall that the surplus is $s=v-v_{\mathrm{ng}}$, where $v_{\mathrm{ng}}$ is the sum of the parties' stand-alone values. 


\subsection{MACs and ex post Efficiency}

The model in Section 3 assumed that the seller's investment would not reduce its stand-alone value; and since the buyer did not invest, this assumption implied that the ex post value of the proposed new company would always equal or exceed $v_{\text {ng }}$, the sum of the parties' stand-alone values. We now consider the possibility that the new company's value turns out to be less than $v_{\mathrm{ng}}$.

In this event, a MAC efficiently reduces the buyer's exit costs relative to the buyer's contract law rights. If there were no MAC and the buyer breached, the seller could not prove market damages because these would be the difference between the contract price and the target's stand-alone value, and, we assume, these values are unverifiable. In such cases, however, courts routinely award specific performance, which would require the buyer to pay $d$. The buyer would complete the deal when $v \geq v_{\text {ng }}$ and purchase the right to exit otherwise. In the latter case, the "breach surplus" - the loss from performance that breach would avoid - is $v_{\text {ng }}-v$. The buyer could exit by paying the price $d$ and a share of this surplus. Therefore renegotiation would yield ex post efficiency under contract law.

A MAC also generates only efficient performances, but where no exceptions apply, the buyer could cancel whenever $v<d$. The parties will renegotiate to perform when $v \geq v_{\text {ng }}$ and let the cancellation stand otherwise. When performance would be inefficient, the buyer's exit price when the agreement has a MAC is zero Therefore, while the parties' ability to avoid inefficient deals is unaffected by whether the agreement has a MAC, efficiency is achieved under a MAC at lower cost. This relaxes buyer participant constraints and thus increases the set of value increasing deals parties can do. We can summarize this logic with

Proposition 3. Parties will conclude only ex post efficient deals, whether the standard acquisition agreement contains a MAC or not, but MACs relax buyer participation constraints relative to contract law.

\section{Data and Analysis}

The symmetry and investment theories support different hypotheses regarding MACs:

$H 1_{S}{ }^{34}$ The traditional MAC clause - a term without exceptions - should become prevalent after 1985.

$H 1_{I}$. The traditional MAC clause should have been used long before 1985.

$H 2_{S}$. MAC exceptions should impose on sellers the risk of exogenously caused declines in the value of the new corporate combination.

34. Subscripts denote theories. Thus $\mathrm{H}_{S}$ is the initial hypothesis of the symmetry theory. 
$H 2_{I(1)}$. MAC exceptions should impose on buyers those exogenous risks whose impact would be felt most strongly after a deal closes.

$H 2_{I(2)}$. MAC exceptions should be more prevalent in industries in which human capital is a significant asset and technological change is rapid.

These hypotheses are discussed in Section 2.2. To summarize briefly, the symmetry theory cannot account for the early existence of MACs because the term functions in the theory only to create an offsetting call to the seller's put option. That option became significant as a consequence of economic and legal developments that took place in the 1980s. In our view, MACs should always have been present because they function to encourage the seller to take affirmative actions that would preserve (or increase) the value that the parties expect the new enterprise to have. This explains the two H1 hypotheses. Regarding $\mathrm{H} 2$, under the symmetry theory, the seller should bear exogenous risk because this makes the buyer's offsetting call option more effective. Under the investment theory, there is no need to impose exogenous risk on the seller, and since the buyer is a more efficient risk bearer than the seller, the buyer should bear this risk. Moreover, the gains to the parties from imposing exogenous risk on the seller are more likely to exceed contracting costs when synergy investments in a deal that fails to close could reduce the target's stand-alone value. For the reasons given above, these are the industries to which $\mathrm{H} 2_{\mathrm{I}(2)}$ refers.

Systematic data on MACs for the years before 1980 are difficult to obtain. Our impressionistic evidence, from experience and memory, lawyer interviews, and the professional literature (see Freund, 1975), suggests that the traditional MAC was widely used in the pre-1980 era, and we are aware of no evidence to the contrary. This record, though unsystematic, is consistent with the investment theory.

We were able to test $\mathrm{H} 2$ more systematically. The set of acquisition agreements on which we report below is insufficient to refute conclusively either theory. Rather, the data are suggestively inconsistent with the symmetry hypotheses and suggestively support the investment hypotheses. This evidence, together with the theory Section 3 develops, cause us to conclude that the investment story best explains the presence of MACs in acquisition agreements and the form that MACs take.

To secure contracts, we downloaded from the SEC's EDGAR site random samples of acquisitions announced in 1993, 1995, and 2000. These samples included the terms "material adverse change," "material adverse event," or both. We then asked whether the traditional MAC formulation - no material adverse change in the business, financial condition, or results of operationswas modified by explicit inclusions or exclusions from the generic formulation. The acquisition agreements were coded for the presence of the following categories of events: (1) changes in global economic conditions; 2) changes in U.S. economic conditions; (3) changes in global stock, capital, or financial market conditions; (4) changes in U.S. stock, capital, or financial market conditions; (5) changes in the economic conditions of other regions; (6) changes in 
the target company's industry; (7) changes in applicable laws or regulations; (8) changes in the target company's stock price; (9) loss of customers, suppliers, or employees; (10) changes due to the agreement or the transaction itself; and (11) a miscellaneous category. The agreements also were coded for two qualifications to the explicit inclusions or exclusions of the traditional MAC definition. These qualifications would make a specified inclusion or exclusion inapplicable if the MAC either specifically affected the target company or had a materially disproportionate effect on the target company. ${ }^{35}$ An analysis of the data from the three sample years appears in Tables 1-3.

The tables reveal a significant shift in transaction practice respecting MACs. In 1993, only $18.33 \%$ of MAC clauses included one or more event specifications that restricted the buyer's right to exit; more than half of these stated a single event. In 1995, the percentage of clauses with an event specification had increased to $31.74 \%$, with an average of 0.67 per transaction. By 2000 , event specifications had become mainstream; $83 \%$ of the sample acquisition agreements featured at least one MAC or MAE exclusion, with an average of 3.75 per transaction.

Table 1 also rejects $\mathrm{H} 2$ s in favor of $\mathrm{H} 2{ }_{\mathrm{I}}$. We observe no evidence that exceptions to MAC clauses have expanded to give acquirers an option to abandon on the occurrence of a value reducing exogenous change to match the target company's option to abandon on the occurrence of a value increasing exogenous change. To the contrary, approximately two-thirds of the transactions in the 2000 sample exclude from the definition of a MAC or MAE the two most obvious examples of exogenous risk: changes in the U.S. economy and changes in the target company's industry.

The data also permit us to distinguish between technology and nontechnology mergers for the years 1995 and $2000 .{ }^{36}$ This evidence is consistent with $\mathrm{H} 2_{\mathrm{I}(2)}$, that the change in acquisition practice may have begun in connection with, and is more significant in, high technology acquisitions. In our analysis, this would be because the danger of reductions in a target's stand-alone value is more serious there. In 1995, 29.6\% of nontechnology acquisition agreements had one or more MAC exclusions, while $44.4 \%$ of technology acquisitions had these exclusions. Section 2.2.2 argues that the risk of customer, supplier, or employee loss is greater in connection with high tech mergers. No agreement in the 1995 sample excluded from the definition of a material adverse change the target company's loss of customers, suppliers, or employees. The 2000 data show that $3.3 \%$ of nontechnology acquisition agreements, but $25.6 \%$ of technology agreements, had such an exclusion.

Section 2.2.2 also argues that high tech firms are more likely to experience a general reduction in stand-alone value from a failed deal. No agreement in the 1995 sample excluded from the definition of a material adverse change

35. This exception to MAC exceptions apparently rests on the view that the seller can cushion the shock of an exogenous change that would affect it, but not similar firms, or that would affect it disproportionately. Such risks therefore seem more endogenous than exogenous.

36. The professional literature claims a special role for MAC exclusions in high technology transactions. See, for example, Howard (1998) and Halloran and Rowland (1999). 
Table 1. Prevalence and Characteristics of MAC and MAE Exclusions for 1993, 1995 and 2000

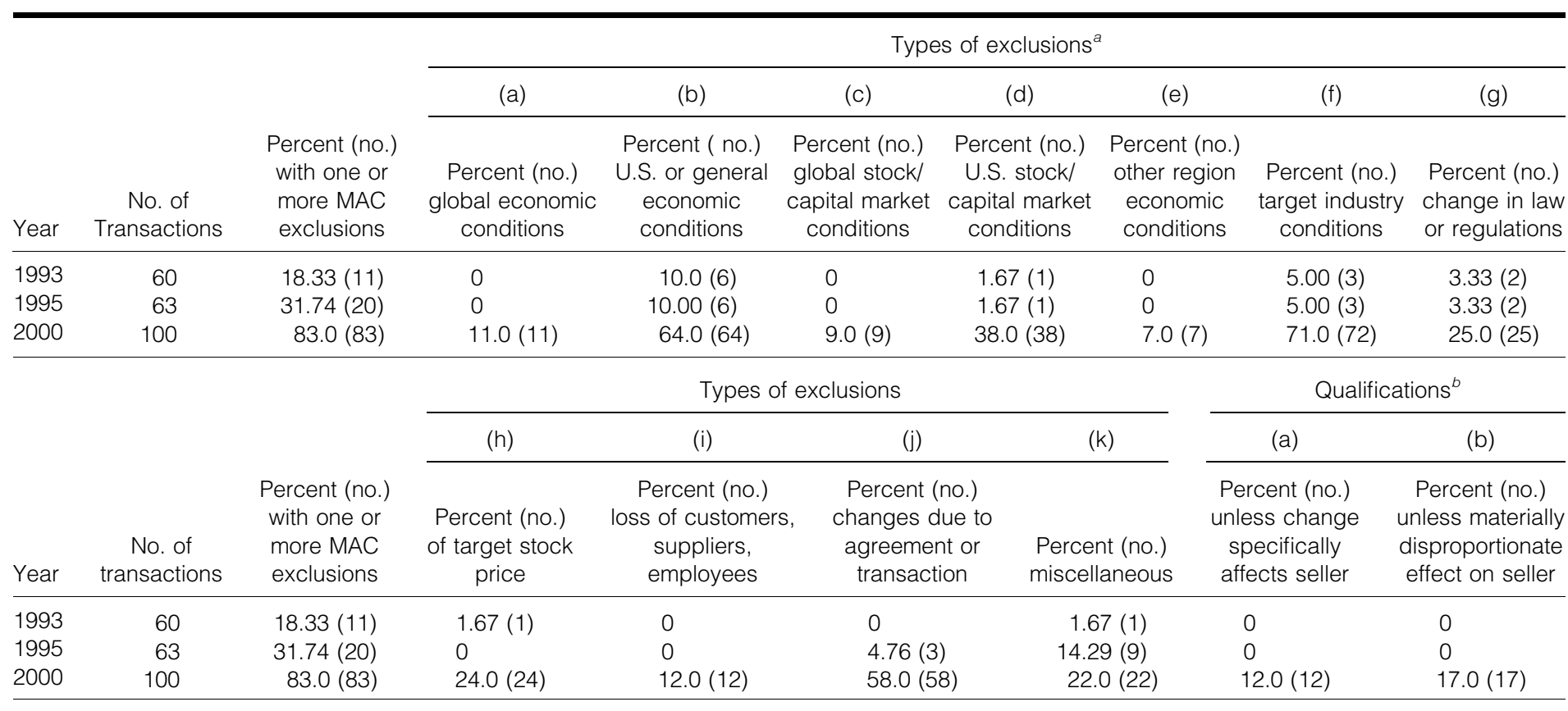

${ }^{a}$ Totals more than $100 \%$.

${ }^{b}$ Qualifies applicability of exclusion; for example, change in U.S. conditions is not excluded if the change specifically affects or has a materially disproportionate effect on the seller. 
Types of exclusions ${ }^{b}$

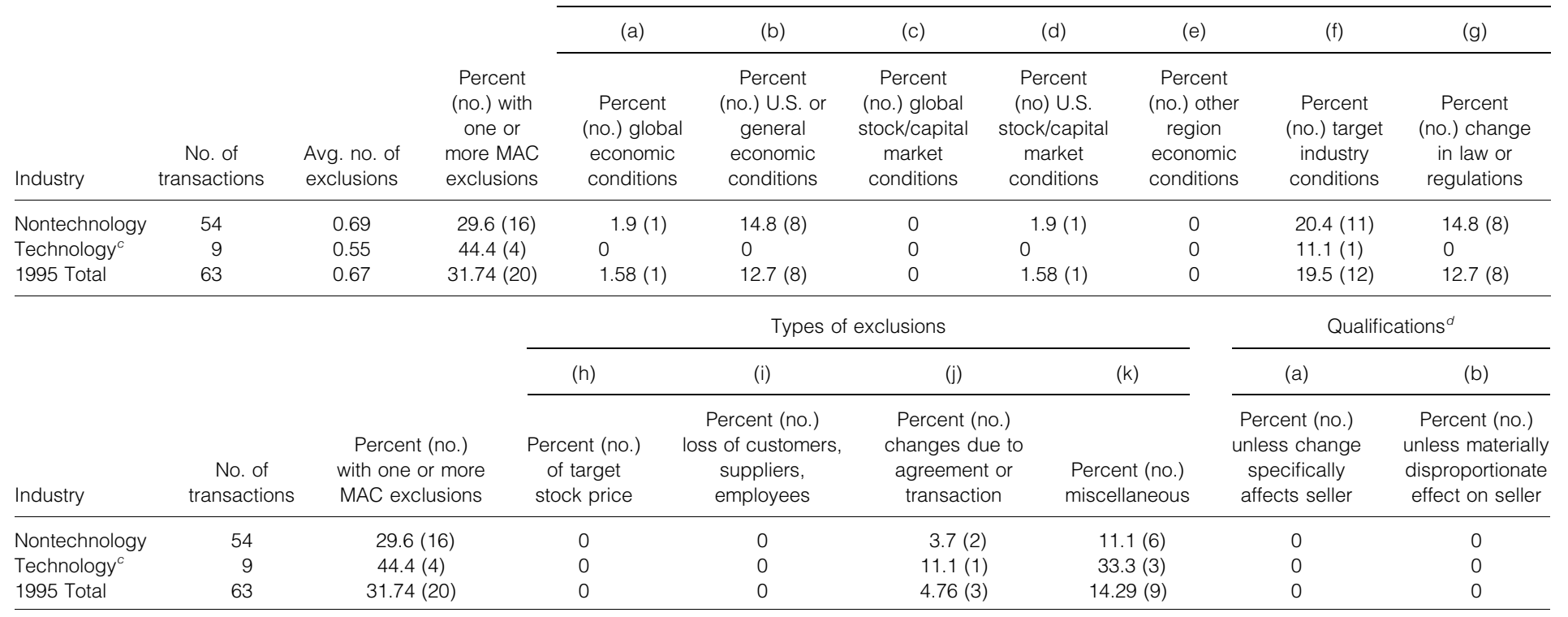

${ }^{a}$ As shown in Table 1, the 1993 sample had too few exclusions to warrant an industry breakdown.

${ }^{b}$ Totals more than $100 \%$.

${ }^{c}$ Technology is defined narrowly in this set to only include engineering, computer, biotech, and industrial instruments, and target companies that plainly involve a high technology component. The classification could not rely on SIC codes because in many industries the classification depends on the product rather than the production technology. So, for example, Internet companies are classified based on the product they sell, rather than the technology associated with marketing.

${ }^{d}$ Qualifies applicability of exclusion; for example, change in U.S. conditions is not excluded if the change specifically affects or has a materially disproportionate effect on the seller. 
Table 3. Prevalence and Characteristics of MAC and MAE Exclusions for 2000 by Industry

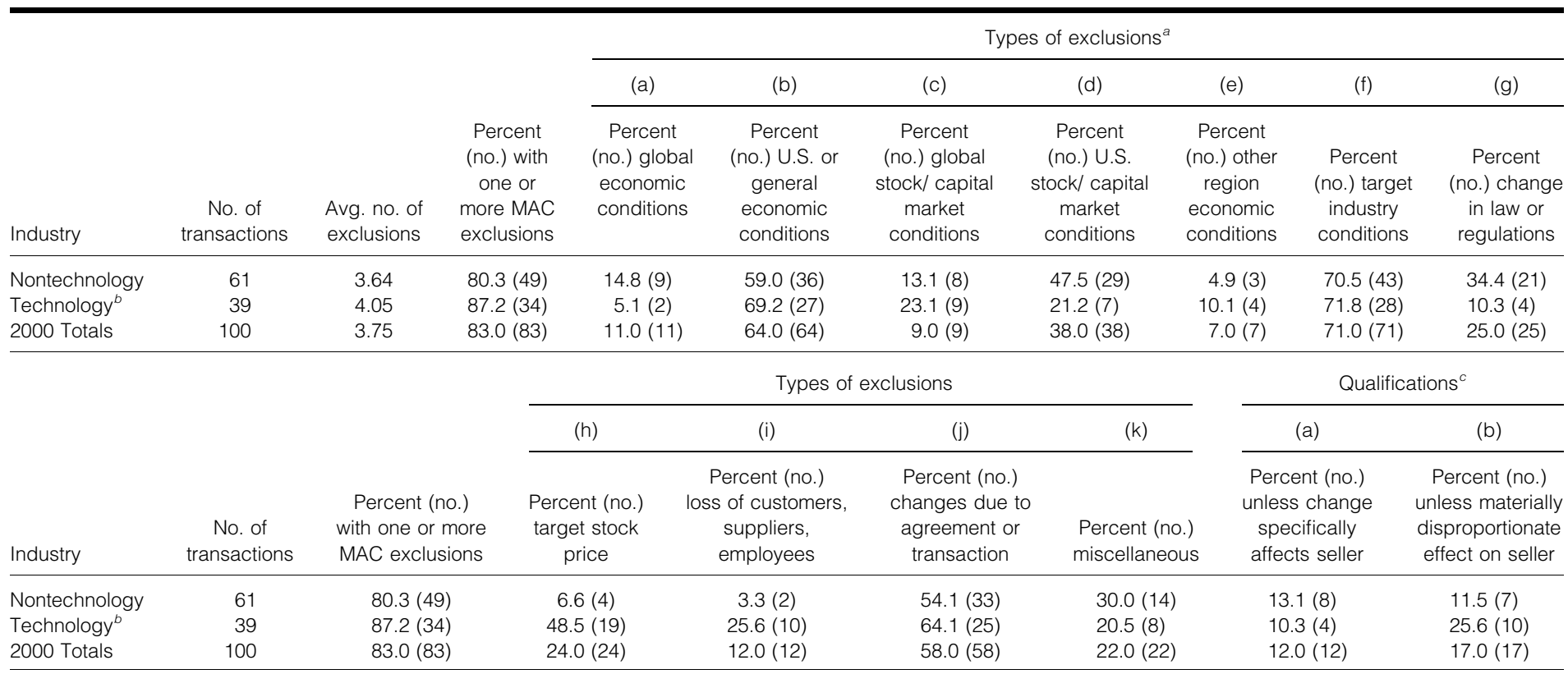

${ }^{a}$ Totals more than $100 \%$.

${ }^{b}$ Technology is defined narrowly in this set to only include engineering, computer, biotech, and industrial instruments, and target companies that plainly involve a high technology component. The classification could not rely on SIC codes because in many industries the classification depends on the product rather than the production technology. So, for example, Internet companies are classified based on the product they sell, rather than the technology associated with marketing.

${ }^{c}$ Qualifies applicability of exclusion; for example, change in U.S. conditions is not excluded if the change specifically affects or has a materially disproportionate effect on the seller. 
a decline in the target company's stock price. The 2000 data indicate that $6.6 \%$ of nontechnology acquisition agreements, but $48.5 \%$ of technology acquisition agreements, had such an exclusion. Such a decline is likely if the target would lose value as a consequence of a failed deal because the market realizes that not all deals close. Moreover, the dramatic increase in exclusions for changes in the target's stock price is also consistent with the increasing volatility that we earlier argued drove the shift from a standard toward rules. In short, and as predicted, parties to technology acquisitions seem more inclined to restrict the buyer's right to exit than parties to acquisitions generally. ${ }^{37}$

It is interesting to speculate briefly on the widespread diffusion of MAC exceptions and the pattern of this spread. The New York Supreme Court's decision, in the Jardine case, ${ }^{38}$ to send to the jury a buyer's invocation of the traditional MAC to justify its exit following a classic exogenous event - the 1987 stock market crash - prompted transaction lawyers to focus on the ambiguity in the traditional MAC formulation regarding exogenous risk. As the analysis in Section 3.3 suggests, the transaction costs of this focus are more likely to be below the gains for technology acquisitions in which the materialization of exogenous risk can cause the most difficulty. An innovation here might have diffused widely through Silicon Valley as a consequence of repeated interactions among networks of M\&A lawyers. ${ }^{39}$

As is apparent from our 2000 sample, the next step was the spread of the new MAC and MAE practices across industries. A number of factors may have influenced this diffusion. Perhaps most interesting, the spread may have been due to the nature of judicial interpretation. Lawyers would expect that judicial construction of a traditional MAC term in a particular transaction would be influenced by changes in MAC terms in other transactions. In particular, how a court resolves the ambiguity in the traditional MAC formulation may be influenced by the practice of parties in other transactions to resolve the ambiguity explicitly. The nature of high tech innovations thus could have affected the construction of traditional MACs in non-high tech deals. Transaction lawyers could come to believe that this increase in juridical risk - the reading in of specific inappropriate inclusions or exclusions - would justify creating explicit modifications to the traditional MAC that fit the deal at issue. We note, however, that the diffusion is more than mere mimicry. In 2000, the exclusions most central to the risk of a decline in stand-alone value if the acquirer did not close in reliance on the MAC - the loss of customer's

37. An experienced Silicon Valley lawyer linked the scope of the MAC clause and the seller's option to exit to the use of different contractual techniques for addressing the symmetry concern, which the data here reject, and the investment concern. The attorney recounted that the negotiation of exceptions to a MAC (which exacerbate the symmetry concern) typically is paired with the negotiation of a narrowly drafted "fiduciary out" (which can mitigate the symmetry concern). The more narrow the fiduciary out, the more difficult it is for the seller to accept a higher priced offer.

38. Bear Stearns Companies, Inc. v. Jardine Strategic Holdings Limited, \#31731/87 (N.Y. Sup. 1988).

39. See Davis (1991) and Davis and Greve (1997) for studies on the spread of legal practice innovations. 
suppliers or employees, and a drop in target stock price - were still more than seven times more likely to appear in agreements involving technology transactions than in agreements involving nontechnology transactions. Conversely, MAC exclusions for changes in law or regulations, likely of greater significance in older, more heavily regulated industries, were in 2000 approximately five times as likely to appear in a nontechnology agreement than in a technology agreement.

\section{Legal and Drafting Implications}

It is beyond the scope of this article to analyze the extensive case law regarding MACs. ${ }^{40}$ However, it is useful to comment briefly here on what is widely thought to be the most important case, the Delaware Court of Chancery's decision, In re IBP, Inc. Shareholders' Litigation [2001 WL 675330 (Del. Ch. 2001)], and we suggest an interpretive criterion for MAC adjudication that follows from our analysis here. The court faced in $I B P$ a traditional, and thus ambiguous, MAC and it attempted to make the term more concrete. A MAC event, the court held, was "a significant diminution of the value of the business entity as a whole." This well-meaning effort to deal with ambiguity in the traditional MAC formulation was unsatisfactory for two reasons. First, parties to acquisition agreements, as we have seen, have begun to negotiate detailed MAC exceptions, thereby lessening the need for a legal default rule. The issue courts now face is how to interpret the contract, not how to fill in the blanks. ${ }^{41}$ Second, the court's proposed default itself is off the mark because it focuses on clarifying the adjective "material" rather than on distinguishing between endogenous and exogenous causes of a decline in the value of the combined company. Materiality refers to the extent of a value change, but had values been verifiable, the MAC term would have conditioned directly on them. Rather, because values are difficult to verify, parties prefer courts to focus on causes. ${ }^{42}$

The investment theory supplies an interpretive criterion for a judicial inquiry into causation. When a buyer attempts to exit by invoking a MAC clause, the

40. We supply an analysis of the cases in a nontechnical treatment of MACs (Gilson and Schwartz, forthcoming).

41. The acquisition agreement in $I B P$ was, coincidently, a part of our 2000 sample. It was unusual in that it was part of the $17 \%$ of the sample that had no MAC exclusions. The court did not consider whether the general change in transactional patterns - in our sample $83 \%$ of the entire sample and $80.3 \%$ of the nontechnology sample addressed at least one element of endogenous risk - should bear on the construction of a provision that retained the traditional ambiguous formulation.

42. A commercial law analogy may be clarifying. The Uniform Commercial Code excuses a seller from performance when subsequent events make performance "impracticable." This phrase directs courts to focus on the loss the seller would have suffered from performance. Profits and losses are difficult to verify, however. Parties thus routinely replace the Uniform Commercial Code with force majure clauses that list verifiable excusing events - fire, war, legal regulation whose materialization would ordinarily prevent the seller from performing or to cause performance costs to increase greatly. 
court should ask whether the event was within the seller's ability to affect. As an example of this distinction, assume a MAC contains an exception regarding economic conditions in the target's industry. The exception should keep the buyer in the deal if a material decrease in the seller's profitability was caused by a sudden, but apparently permanent, increase in imports in the industry. On the other hand, the presumption should be that the buyer would be permitted to exit if the decline was caused by an increase in input costs against which the seller could have, but did not, hedge.

Here, however, the analysis is completed by shifting attention to the concept of "change" in the MAC formulation. If it had not been the practice of firms such as the seller to hedge the particular risk, then, we suggest, the relevant change should be held to be exogenous - the realization of an external riskrather than endogenous, that is, caused by actions the seller took or failed to take.

Interpretive criteria for MACs are an important subject because the current inventory of MAC exclusions retain what may be an inherent, standard-like ambiguity. For example, consider in light of the interpretation of the "change" requirement we just suggested the qualification to the exception that permits a buyer to exit when exogenous events that otherwise would have been covered by an exception to the MAC clause have a disproportionate impact on the seller. ${ }^{43}$ Such a disproportionate impact could be relevant to interpretation in two opposing ways. First, it may suggest that the target had actions available to it that would have prevented or lessened the impact of the apparently exogenous event. If so, the exception to the exception should apply, so that the buyer could exit if it wished. Second, the impact may be a consequence of the seller following a high beta strategy that was efficient for it; the seller, that is, may have been investing less in risk cushioning activities and more in production activities than some of its competitors. If so, the exception to the exception probably should not apply because it is uncommon for parties to intend a seller to take actions that would differ materially from its pretransaction practice without saying so; costly, deviant actions would usually be an expressed part of the agreement's operating covenants were they meant to be taken. ${ }^{44}$ Thus the exclusion's proportionality measure would require a change in the company's pre-event sensitivity to industry changes.

More detailed analysis of interpretive criteria for MACs awaits further research, but we offer two concluding remarks. Initially, courts sometimes appear to suspect that a buyer who invokes a MAC is merely reneging on a deal that turned sour. Such courts attempt to resolve ambiguities in the MAC against the buyer. This attitude is in considerable part mistaken, because it is the threat of buyer exit that efficiently increases the seller's incentive to take

43. See the text at note 35 and note 35 . These exceptions appeared in none of our 1993 contracts, but in $17 \%$ of the 2000 contracts.

44. It is commonplace among the covenants governing the target's conduct of its business during the period between execution and closing that it not change its business practices without the consent of the acquirer. From this perspective, business practices whose change would require the acquiring company's consent would be taken as given in interpreting the MAC clause. 
actions that reduce the probability of bad realizations. Second, parties could aid courts by prefacing the MAC term with a discursive statement of what they intended the term to promote and to avoid. As an example, the parties could ask courts to use the interpretive criterion suggested here. Such a drafting approach would leave courts with much less discretion than the IBP court actually had or wanted to have; rather, a court's residual discretion would be channeled in a fashion that would reflect the parties' now explicit goals.

\section{Conclusion}

Hundreds of billions of dollars of assets transfer each year under what is essentially the same acquisition agreement. This agreement has received little academic analysis despite its commercial significance. Our article begins such an analysis by examining an important set of acquisition terms, the material adverse change clause and the material adverse event clause. We ask why these terms are in the agreement and why their formulation has changed substantially over the years.

We conclude that the clauses' presence results from two problems that parties to acquisitions face, both of which are a consequence of the sometimes lengthy interim between the signing of an acquisition agreement and its closing. The first problem is to induce the seller to make efficient value preserving and value enhancing investments in the transaction; the second problem is to induce the buyer to take precautions against or to insure against exogenous events that could reduce the value of the new combination. These problems require creative contractual solutions because, we assume, courts cannot observe the value of the posttransaction combination or the value affecting actions that a seller and buyer could take, and it would be too costly for parties to create behavorial codes that courts could merely enforce.

The MAC solves these problems in a simple, but nice way. The traditional MAC permits a buyer to exit when a material adverse change or effect would make the deal unprofitable for it. The buyer's exit right encourages the seller to take actions that would protect and possibly enhance the value the new company is expected to have. The set of MAC exceptions, in contrast, encourages the buyer to take actions that would protect the new company against the materialization of risks that neither party could prevent, but that the buyer could best affect. The MAC term thus allocates transaction risks to the party that can most efficiently bear them.

We also report the results of our empirical analysis of actual MAC terms. These results are consistent with the explanations we advance here. In particular, our theory predicts that MACs have been in use for a long time; that ambiguities in MACs will be resolved by allocating endogenous risk to sellers and exogenous risk to buyers; and that MAC exceptions are more likely to appear in cases when a failed deal would reduce the seller's stand-alone value. The data we present support these predictions. And finally, our analysis supplies criteria that could aid courts when interpreting MACs. We uncover the parties objectives in writing this term - to create incentives for the party that 
can best preserve or increase value to do so. The interpretive task should be eased for courts when they understand what the parties are attempting to achieve.

\section{References}

Andrade, Gregor, Mark Mitchell, and Erik Stafford. 2001. "New Evidence and Perspectives on Mergers," 15 Journal of Economic Perspectives 103-20.

Bates, Thomas W., and Michael L. Lemmon. 2003. "Breaking Up is Hard to Do? An Analysis of Termination Fee Provisions and Merger Outcomes," 69 Journal of Financial Economics 469-504.

Davis, Gerald F. 1991. "Agents Without Principles: The Spread of the Poison Pill Through the Intercorporate Network,” 36 Administrative Science Quarterly 583-613.

Davis, Gerald F., and Henrich R. Greve. 1997. "Corporate Elite Networks and Governance Changes in the 1980s," 103 American Journal of Sociology 1-37.

Edlin, Aaron, and Alan Schwartz. 2003. "Optimal Penalties in Contracts," 78 Chicago Kent Law Review 33-54.

Freund, James. 1975. Anatomy of a Merger: Strategies and Techniques for Negotiating Corporate Acquisitions. New York: Law Journal Press, 259-61 .

Freund, James, and Richard Easton. 1979. "The Three-Piece Suitor: An Alternative Approach to Negotiated Corporate Acquisitions," 34 Business Lawyer 1679-724.

Gilson, Ronald J. 1982. "Seeking Competitive Bids Versus Pure Passivity in Tender Offer Defense," 35 Stanford Law Review 51-67.

—. 1984. "Value Creation by Business Lawyers: Legal Skills and Asset Pricing," 89 Yale Law Journal 239-313.

-. Forthcoming 2005. "Catalyzing Corporate Governance: The Evolution of the American System in the 1980s," in T. Heller and M. Klausner, eds. The Ecology of Corporate Governance.

Gilson, Ronald J., and Bernard S. Black. 1995. The Law and Finance of Corporate Acquisitions, 2nd ed. Westbury, NY: Foundation Press.

Gilson, Ronald J., and Alan Schwartz. Forthcoming 2005. The Evolution of MACs. Working paper.

Halloran, Michael J., and D. Stanley Rowland. 1999. "Changes in Material Adverse Change Provisions in High Tech Deals," 2(10) $M \&$ \& Lawyer 12-15.

Hart, Oliver, and John Moore. 1999. "Foundations of Incomplete Contracts," 66 Review of Economic Studies 115-38.

Howard, Rodrigo J. 1998. "Allocating the Risks of Interim Changes: MACs and MAEs in Recent Technology M \& A Agreements," in Drafting Corporate Agreements 1998-1999. New York: Practicing Law Institute.

Maskin, Eric, and Jean Tirole. 1999. "Unforeseen Contingencies and Incomplete Contracts," 66 Review of Economic Studies 83-114.

Schwartz, Alan, and Robert E. Scott. 2003. "Contract Theory and the Limits of Contract Law," 113 Yale Law Journal 541-619.

Schwartz, Alan, and Joel Watson. 2004. "The Law and Economics of Costly Contracting," 20 Journal of Law, Economics, \& Organization 2-31.

Sorkin, Andrew, and Jonathan Glater. 2001. "Merger Deals are Stalled Amid Doubt: Attack may be Invoked to Cancel Agreements," New York Times, September 17, C1.

Tam, Pui-Wing. 2003. "An Elaborate Plan Forces H-P to Stay on Target," Wall Street Journal, April 28, A1.

Thurm, Scott. 2002. "HP, Compaq Plan the Details of Their Union," Wall Street Journal, January 25, A13.

Thurm, Scott, Pui-Wing Tam, and Gary McWilliams. 2003. "Nail Biter: HP Claims Victory on Compaq Merger," Wall Street Journal, March 20, A1. 